\title{
Fertility preservation during cancer treatment: clinical guidelines
}

\author{
This article was published in the following Dove Press journal: \\ Cancer Management and Research \\ 4 March 2014 \\ Number of times this article has been viewed
}

\author{
Kenny A Rodriguez- \\ Wallberg ${ }^{1,2}$ \\ Kutluk Oktay 3,4 \\ 'Karolinska Institutet, Department \\ of Clinical Science, Intervention and \\ Technology, Division of Obstetrics \\ and Gynecology, ${ }^{2}$ Reproductive \\ Medicine, Karolinska University \\ Hospital Huddinge, Stockholm, \\ Sweden; ${ }^{3}$ nnovation Institute for \\ Fertility Preservation, Rye and New \\ York, ${ }^{4}$ Department of Obstetrics \\ and Gynecology, New York Medical \\ College, Valhalla, NY, USA
}

Correspondence: Kenny A RodriguezWallberg

Reproductive Medicine, Karolinska University Hospital Huddinge, Novumhuset Plan 4, SE-I4I 86 Stockholm, Sweden

Email kenny.rodriguez-wallberg@ karolinska.se

Kutluk Oktay

Innovation Institute for Fertility

Preservation, $139 \mathrm{E} 23 \mathrm{rd}$ St,

New York, NY I0010, USA

Email koktay@fertilitypreservation.org
Abstract: The majority of children, adolescents, and young adults diagnosed with cancer today will become long-term survivors. The threat to fertility that cancer treatments pose to young patients cannot be prevented in many cases, and thus research into methods for fertility preservation is developing, aiming at offering cancer patients the ability to have biologically related children in the future. This paper discusses the current status of fertility preservation methods when infertility risks are related to surgical oncologic treatments, radiation therapy, or chemotherapy. Several scientific groups and societies have developed consensus documents and guidelines for fertility preservation. Decisions about fertility and imminent potentially gonadotoxic therapies must be made rapidly. Timely and complete information on the impact of cancer treatment on fertility and fertility preservation options should be presented to all patients when a cancer treatment is planned.

Keywords: fertility preservation, cancer, cryopreservation, ovarian tissue transplantation, fertility-sparing surgery, cancer survival, quality of life

\section{Introduction}

The number of reported new cancer cases is increasing every year. In the Swedish Cancer Registry, the validity of which relies on the inclusion of approximately $98 \%$ of cases having morphologic verification, the average annual increase has been $2.1 \%$ for men and $1.5 \%$ for women during the last two decades. ${ }^{1}$ Only about half of this increase is explained by aging of the population and in many cases cancer patients are very young. Similar data have been observed in other European countries and in the US. ${ }^{2}$ The good news is that the probability of surviving cancer today is high and is continually improving. Rates of survival today are above $80 \%$ for various cancer types, in particular for very young patients, such as those presenting with cancer in childhood or early adulthood. ${ }^{3}$ Survivorship issues have therefore become highly relevant as well as quality of survival encompassing all health aspects.

The diagnosis of cancer at a young age, when individuals may have not yet started their families, poses unique challenges because treatments for cancer may induce ovarian or testicular failure by damaging ovarian follicles in females and spermatogonia in the testis in males. Gonadal failure may affect all aspects of reproductive health, including pubertal development, hormone production, and sexual function in adults. When cancer is treated by surgery, fertility may be impaired by removal or damage of the organs needed for reproduction.

The gonadotoxic effects of chemotherapy and radiation therapy are well recognized. These are dose-dependent and have been well characterized regarding the protocols used..$^{3-12}$ Radiotherapy in females may also damage the uterus. ${ }^{13,14}$ Gonadotoxicity is 
particularly dependent on age in females, because the number of primordial follicles making up the female ovarian reserve is nonrenewable and diminishes steadily over the years until complete follicle depletion, which denotes menopause onset. Given that women who are older have a reduced reserve of eggs when compared with younger women, their risk of developing permanent ovarian failure is higher, whereas the risk may be relatively low in young women and girls following similar treatments. ${ }^{14}$ If young patients present with apparently normal ovarian functioning after completion of cancer treatment, their reproductive period might be reduced and adequate reproductive counseling is recommended. ${ }^{15}$

In males, spermatogenesis may still continue over several years if the spermatogonian cell population is not completely depleted. If a population of these germ stem cells remains after cancer treatment, regeneration of spermatozoa may continue for years. ${ }^{16}$

The ability to start a family and have children is a key quality of life issue. Because infertility following cancer treatment has a recognized negative impact on quality of survival, ${ }^{17-21}$ several multidisciplinary groups and societies have made great effort in reviewing the currently available data on fertility preservation to produce guidelines for health care providers. Options to preserve fertility potential are currently available, and fertility preservation has emerged as a novel field where experience from disciplines such as oncology, surgery, reproductive medicine, psychology, and ethics are crossing over, and additional medical and paramedical disciplines are currently joining in. However, many inequalities for cancer patients in their access to counseling and fertility preservation have been reported. ${ }^{22-24}$

It is difficult to estimate the size of the population that may be interested in fertility preservation. Further, the risk of infertility differs depending on the type of cancer, treatment required, and age of the patient. The desired number of children is a very individual wish, and patients in similar clinical circumstances may have different wishes. For males, it is difficult to define a "reproductive age", and regardless of age, a man could preserve sperm for the future, whereas the age-related follicle depletion in females, which occurs several years before onset of menopause, clearly denotes the end of the reproductive period.

\section{Risk of cancer in young males and females}

For men and women, the overall risk of developing cancer at some time during life is about $45 \%$ and $37 \%$, respectively. ${ }^{25}$ That risk increases with age in both sexes, and for people below 39 years of age, the risk is about $1 / 72$ for men and $1 / 51$

Table I Ten leading cancer types for the estimated new cancer cases and deaths by sex, United States, 2014

\begin{tabular}{|c|c|c|c|c|c|}
\hline \multicolumn{6}{|l|}{ Estimated new cases" } \\
\hline \multicolumn{6}{|c|}{ Males Females } \\
\hline Prostate & 233,000 & $27 \%$ & Breast & 232,670 & $29 \%$ \\
\hline Lung and bronchus & 116,000 & $14 \%$ & Lung and bronchus & 108,210 & $13 \%$ \\
\hline Colorectum & 71,830 & $8 \%$ & Colorectum & 65,000 & $8 \%$ \\
\hline Urinary bladder & 56,390 & $7 \%$ & Uterine corpus & 52,630 & $6 \%$ \\
\hline Melanoma of the skin & 43,890 & $5 \%$ & Thyroid & 47,790 & $6 \%$ \\
\hline Kidney and renal pelvis & 39,140 & $5 \%$ & Non-Hodgkin lymphoma & 32,530 & $4 \%$ \\
\hline Non-Hodgkin lymphoma & 38,270 & $4 \%$ & Melanoma of the skin & 32,210 & $4 \%$ \\
\hline Oral cavity and pharynx & 30,220 & $4 \%$ & Kidney and renal pelvis & 24,780 & $3 \%$ \\
\hline Leukemia & 30,100 & $4 \%$ & Pancreas & 22,890 & $3 \%$ \\
\hline Liver and intrahepatic bile duct & 24,600 & $3 \%$ & Leukemia & 22,280 & $3 \%$ \\
\hline All sites & 855,220 & $100 \%$ & All sites & 810,320 & $100 \%$ \\
\hline \multicolumn{6}{|l|}{ Estimated deaths } \\
\hline \multicolumn{6}{|c|}{ Males Females } \\
\hline Lung and bronchus & 86,930 & $28 \%$ & Lung and bronchus & 72,330 & $26 \%$ \\
\hline Prostate & 29,480 & $10 \%$ & Breast & 40,000 & $15 \%$ \\
\hline Colorectum & 26,270 & $8 \%$ & Colorectum & 24,040 & $9 \%$ \\
\hline Pancreas & 20,170 & $7 \%$ & Pancreas & 19,420 & $7 \%$ \\
\hline Liver and intrahepatic bile duct & 15,870 & $5 \%$ & Ovary & 14,270 & $5 \%$ \\
\hline Leukemia & 14,040 & $5 \%$ & Leukemia & 10,050 & $4 \%$ \\
\hline Esophagus & 12,450 & $4 \%$ & Uterine corpus & 8,590 & $3 \%$ \\
\hline Urinary bladder & $1 \mathrm{I}, 170$ & $4 \%$ & Non-Hodgkin lymphoma & 8,520 & $3 \%$ \\
\hline Non-Hodgkin lymphoma & 10,470 & $3 \%$ & Liver and intrahepatic bile duct & 7,130 & $3 \%$ \\
\hline Kidney and renal pelvis & 8,900 & $3 \%$ & Brain and other nervous system & 6,230 & $2 \%$ \\
\hline All sites & 310,010 & $100 \%$ & All sites & 275,710 & $100 \%$ \\
\hline
\end{tabular}

Notes: *Estimates are rounded to the nearest 10 and exclude basal cell and squamous cell skin cancers and in situ carcinoma except urinary bladder. Reproduced with permission from John Wiley and Sons. Siegel, R, Ma, J, Zou, Z, Jemal, A. Cancer statistics, 20I4. CA: A Cancer Journal for Clinicians. 2014;64:9-29.26 C) 20I4 American Cancer Society, Inc. 
for women. In the age range of 40-59 years, the risk increases further to $1 / 12$ for men and 1/11 for women. Given that the current trend in Western societies is to delay childbearing until later in life, there will be more young adults presenting with cancer who have not yet started their families and are interested in preserving their fertility. The most frequent cancer diagnoses in young adults and expected new cases in the US for the year 2014 are shown in Table $1 .^{26}$

\section{Risk of infertility after cancer treatment and what can be offered}

Local and systemic treatment modalities for cancer may affect fertility. This paper discusses fertility preservation approaches in oncologic surgery and in patients facing fertility threats due to radiation therapy and chemotherapy. Biological therapy is not discussed, given that its impact on reproduction is largely unknown. Hormonal treatment for cancer, which is targeted to specific hormone receptors, is discussed with regard to hormone-sensitive breast cancer. Figure 1 shows the strategies for fertility preservation depending on the type of cancer treatment.

\section{Fertility-sparing surgery}

Surgical techniques aiming at preserving the reproductive organs without compromising survival are relatively recent and the procedures are still evolving. Indications for fertility-sparing surgery include, in general, a well differentiated low-grade tumor in its early stages or with low malignant potential.

\section{Fertility-sparing surgery in females}

The global rates of fertility-sparing surgery in females are currently unknown. Table 2 presents a compilation of data on female patients with gynecologic cancer undergoing conservative surgery aiming at preserving fertility. Young women presenting with borderline ovarian tumors may be offered a single oophorectomy, and this procedure appears to be safe with regard to oncologic outcome. ${ }^{14}$ Another well-established surgical procedure for fertility preservation in young women is radical trachelectomy. ${ }^{27}$ This may be offered in cases of early-stage invasive cervical cancer. Data on nearly 1,500 cases have been published, mostly from European countries, Japan, the US, Canada, China, and Argentina. ${ }^{28-33}$ A vaginal approach to radical trachelectomy was undertaken in about two thirds of these cases, and approximately 300 pregnancies resulting in live births, half being premature, have been reported. ${ }^{34}$ An abdominal approach to trachelectomy was undertaken in the remaining 485 cases. Although 413 of these women were regarded as fertile after the procedure, only $113(38 \%)$ attempted a pregnancy and 67 achieved a live birth (59.3\%). ${ }^{35}$ Cervical stenosis and subfertility are common after this type of surgery but, in general, the procedures appear to be safe, with no major complications recognized and no higher risk of recurrence having been observed. Recent reports suggest that patients with stage I cervical cancer $2-4 \mathrm{~cm}$ in diameter may also be offered a radical trachelectomy in selected cases, after negative nodal metastasis findings following laparoscopic

If the treatment includes: The following options should be considered:

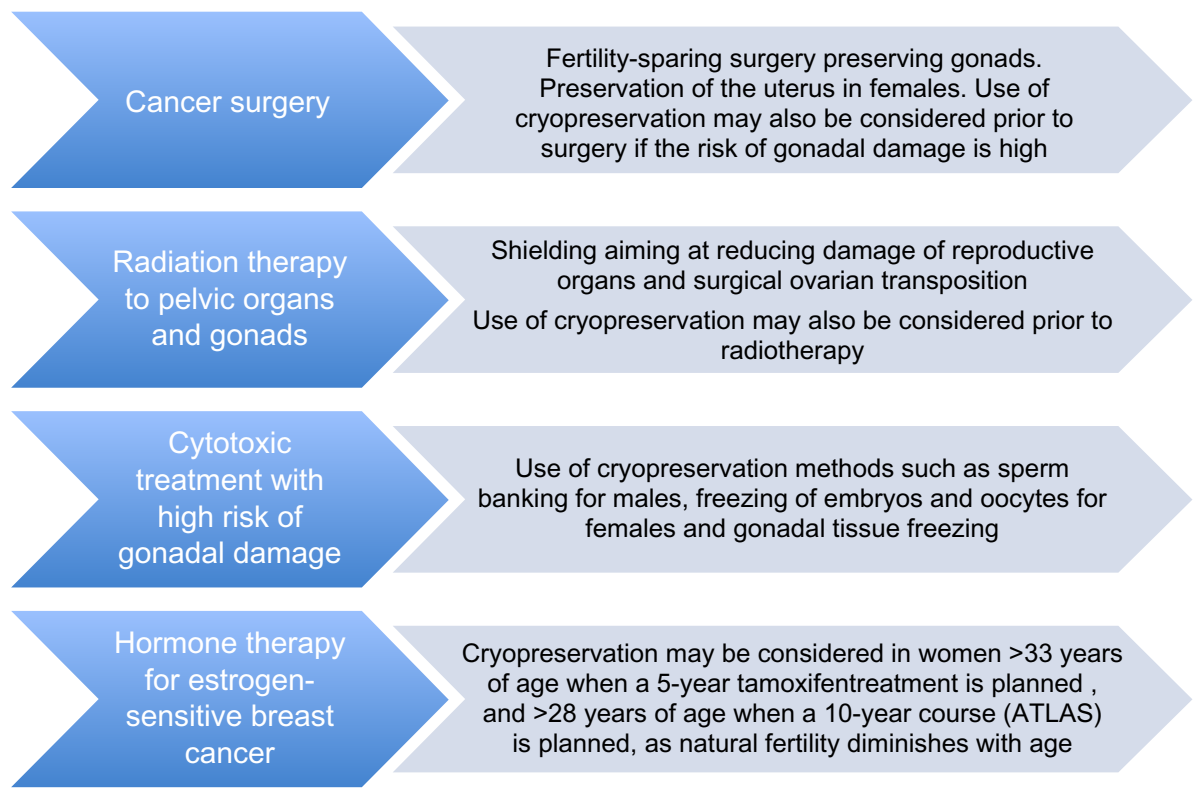

Figure I Fertility preservation strategies depending on the type of oncological treatment in females and males. Note: Image provided courtesy of Rodriguez-Wallberg and Oktay, 2014. 
Table 2 Fertility-sparing interventions in female patients

\begin{tabular}{|c|c|c|c|c|}
\hline Diagnosis & Type of surgery & Description & Obstetric outcome & Oncologic outcome \\
\hline $\begin{array}{l}\text { Cervical cancer } \\
\text { stage }|A|,|A 2,| B \mid\end{array}$ & $\begin{array}{l}\text { Radical vaginal } \\
\text { trachelectomy }\end{array}$ & $\begin{array}{l}\text { Laparoscopic pelvic } \\
\text { lymphadenectomy. Vaginal } \\
\text { resection of the cervix and } \\
\text { surrounding parametria } \\
\text { keeping the corpus of the } \\
\text { uterus and the ovaries intact }\end{array}$ & $\begin{array}{l}\text { Spontaneous pregnancies } \\
\text { described in up to } 70 \% . \\
\text { Risk of second trimester } \\
\text { pregnancy loss and preterm } \\
\text { delivery }\end{array}$ & $\begin{array}{l}\text { Rates of recurrence and mortality } \\
\text { are comparable with those } \\
\text { described for similar cases treated } \\
\text { by radical hysterectomy or } \\
\text { radiation therapy }\end{array}$ \\
\hline $\begin{array}{l}\text { Borderline ovarian } \\
\text { tumors FIGO stage I }\end{array}$ & $\begin{array}{l}\text { Unilateral } \\
\text { oophorectomy }\end{array}$ & $\begin{array}{l}\text { Removal of the affected ovary } \\
\text { only, keeping in place the } \\
\text { unaffected one and the uterus }\end{array}$ & $\begin{array}{l}\text { Pregnancies have been } \\
\text { reported with a favorable } \\
\text { obstetric outcome }\end{array}$ & $\begin{array}{l}\text { Oncologic outcome is comparable } \\
\text { with the more radical approach } \\
\text { of removing both ovaries and } \\
\text { the uterus. Recurrence } 0 \%-20 \% \\
\text { versus } 12 \%-58 \% \text { when only } \\
\text { cystectomy was performed }\end{array}$ \\
\hline $\begin{array}{l}\text { Ovarian epithelial } \\
\text { cancer stage I, grade I }\end{array}$ & $\begin{array}{l}\text { Unilateral } \\
\text { oophorectomy }\end{array}$ & $\begin{array}{l}\text { Removal of the affected ovary } \\
\text { only, keeping in place the } \\
\text { unaffected one and the uterus }\end{array}$ & $\begin{array}{l}\text { Pregnancies have been } \\
\text { reported with a favorable } \\
\text { obstetric outcome }\end{array}$ & $\begin{array}{l}7 \% \text { recurrence of the ovarian } \\
\text { malignancy and } 5 \% \text { deaths }\end{array}$ \\
\hline $\begin{array}{l}\text { Malignant ovarian germ } \\
\text { cell tumors/sex cord } \\
\text { stromal tumors }\end{array}$ & $\begin{array}{l}\text { Unilateral } \\
\text { oophorectomy }\end{array}$ & $\begin{array}{l}\text { Removal of the affected } \\
\text { ovary only }\end{array}$ & $\begin{array}{l}\text { Pregnancies have been } \\
\text { reported and favorable } \\
\text { obstetric outcome }\end{array}$ & $\begin{array}{l}\text { Risk of recurrence similar to } \\
\text { historical controls }\end{array}$ \\
\hline $\begin{array}{l}\text { Endometrial } \\
\text { adenocarcinoma grade I, } \\
\text { stage IA (without } \\
\text { myometrial or cervical } \\
\text { invasion) }\end{array}$ & $\begin{array}{l}\text { Hormonal treatment } \\
\text { with progestational } \\
\text { agents for } 6 \text { months }\end{array}$ & $\begin{array}{l}\text { Follow-up with endometrial } \\
\text { biopsies every } 3 \text { months }\end{array}$ & $\begin{array}{l}\text { Pregnancies have been } \\
\text { reported }\end{array}$ & $\begin{array}{l}\text { Recurrence rate } 30 \%-40 \% \text {; } \\
5 \% \text { recurrence during } \\
\text { progesterone treatment }\end{array}$ \\
\hline
\end{tabular}

Notes: This material is reproduced with permission of John Wiley \& Sons, Inc. Wallberg KA, Keros V, Hovatta O. Clinical aspects of fertility preservation in female patients. Pediatr Blood Cancer. 2009;53(2):254-260. Copyright (2009 Wiley-Liss, Inc.). ${ }^{14}$ For additional information see Sonoda et al, ${ }^{133}$ Morris et al, ${ }^{134}$ Morice et al, ${ }^{135}$ Tangir et al, ${ }^{136}$ and Seli and Tangir. ${ }^{137}$

Abbreviation: FIGO, International Federation of Gynecology and Obstetrics.

pelvic and para-aortic lymphadenectomy for staging ${ }^{36}$ or whenever para-aortic nodes are not involved and frozen sections taken intraoperatively had provided safe results. ${ }^{37}$ However, in these series, $45 \%$ of patients required immediate hysterectomy or chemoradiotherapy owing to high-risk features on final pathology.

A recent European study has raised concerns regarding the need to centralize fertility-sparing surgery at accredited units to ensure a sufficient number of patients at each center aiming at maintaining quality of health care, given that the incidence observed after collecting data from several countries has been low. ${ }^{38}$ Fertility-sparing surgery has also been reported in pregnant women, including abdominal radical trachelectomy ${ }^{39}$ and vaginal trachelectomy with lymphadenectomy, ${ }^{40}$ resulting in live births and preservation of fertility.

\section{Fertility-sparing surgery in males}

Oncologic surgery for prostate, bladder, or colon cancer may damage nerves and affect potency or ejaculation. In patients presenting with testicular cancer, hormone secretion and sperm production may be preserved by performing a partial orchiectomy, which has become an established method for selected patients. In particular, a conservative approach should be undertaken when the testicular mass is small and radical orchiectomy may result in anorchia. ${ }^{41}$ The German Testicular Cancer Study Group reported a 98.6\% disease-free survival rate at 7-year follow-up after conservative surgery for tumors $<2 \mathrm{~cm}$ in 73 patients. ${ }^{42}$ However, the benefits must be weighed against the risk of tumor recurrence in these patients. It may advisable to offer sperm banking prior to surgery, even to patients who may consider a partial orchiectomy at the outset (Figure 1). Successful cases of sperm retrieval from the cancerous testicle in men with azoospermia at the time of radical orchiectomy have been reported, as well as sperm extraction from the epididymis and vas deferens of the orchiectomy specimen. Sperm obtained in this way has been cryopreserved and its use in fertility treatment has resulted in live births. ${ }^{43,44}$ Sperm may also be recovered from the contralateral noncancerous testicle at the time of orchiectomy in patients with azoospermia. ${ }^{45}$

\section{Fertility preservation options for females and males undergoing radiotherapy}

Radiation therapy is used for several cancers in young patients and may be applied in a field affecting the reproductive organs in cases of Hodgkin's disease, Ewing's sarcoma, gynecologic 
cancer, and prostate cancer. In both sexes, the gonads are very sensitive to radiotherapy, and the extent of damage depends on the dose, fractionation schedule, and irradiation field. ${ }^{46-48}$ Total body irradiation given in conjunction with myeloablative conditioning prior to bone marrow transplantation is associated with a high risk of gonadal failure in both sexes. ${ }^{49,50}$ In prepubertal patients, failure of pubertal development may be the first sign of gonadal failure. ${ }^{50}$ Table 3 presents a compilation of current knowledge on the impact of radiation doses and age at radiotherapy in females and males. ${ }^{48}$

In females, all reproductive organs may suffer damage by direct irradiation if they are included in the irradiation field, but can also be damaged by scattered radiation, even after shielding. The degree and persistence of ovarian damage is influenced by the ovarian reserve and age at the time of exposure to radiotherapy. Thus, older women who present with a reduced number of follicles in the ovaries are at higher risk of permanent ovarian failure. ${ }^{11}$ In general, a dose of about 2 Gy applied to the gonadal area may destroy up to $50 \%$ of the ovarian follicle reserve. Irradiation of the vagina is related to fertility and sexual issues due to loss of lubrication, anatomic impairment, and in some cases vaginal stenosis. Radiotherapy of the uterus in young women and girls causes tissue fibrosis, leading to restricted uterine capacity and blood flow, and damage to the uterus seems to be more pronounced in women who are younger at the time of radiotherapy. ${ }^{51}$ Impaired uterine growth during pregnancy and unfavorable pregnancy

Table 3 Radiation therapy protocols with high or intermediate impact on ovarian and testicular function

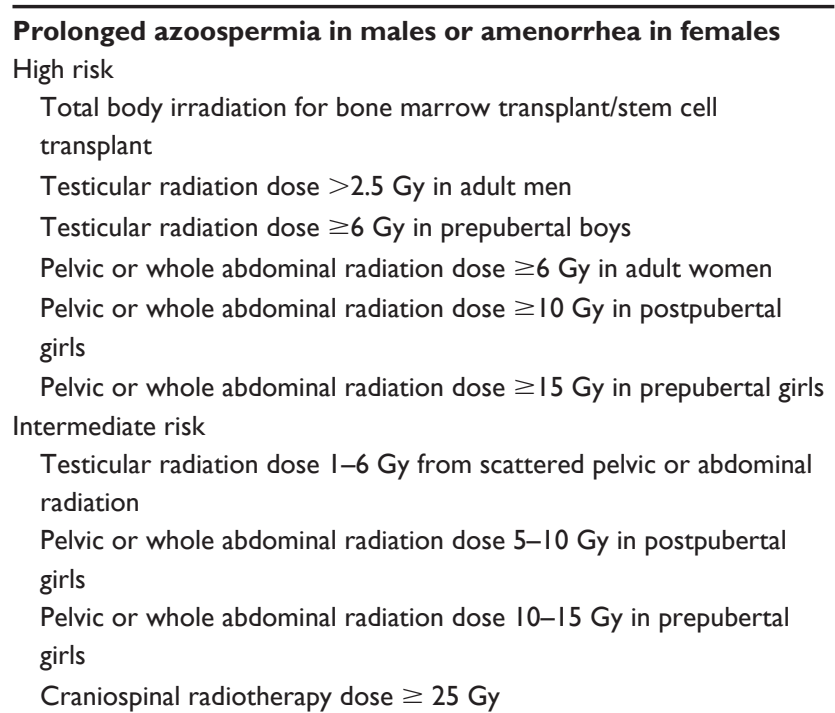

Note: Reprinted with permission from Rodriguez-Wallberg KA, Oktay K. Fertility preservation medicine: options for young adults and children with cancer. J Pediatr Hematol Oncol. 32(5):390-396. ${ }^{48}$ outcomes, including spontaneous abortion, premature labor, and low birth weight offspring, have been reported in women who had undergone radiotherapy to the uterus. ${ }^{13,51}$

In males, the spermatogonia are extremely sensitive to radiation, regardless of age. Leydig cells, on the other hand, are highly sensitive to radiation before puberty onset, ${ }^{52}$ whereas in adulthood, the cells become more resistant, and adult patients may retain Leydig cell function and testosterone production despite becoming azoospermic.

For females and males, both adult and prepubertal, shielding of the gonadal area is the standard procedure for reducing scatter radiation to the reproductive organs and to preserve fertility. Surgical ovarian transposition in females has been practiced and has been shown to reduce the risk of ovarian failure by about $50 \% .{ }^{53}$ Failure of this procedure is related to scatter radiation and damage to the blood vessels supplying the ovaries. ${ }^{53}$

In adult patients, cryopreservation techniques, such as sperm banking for males and embryo and oocyte banking for females, both of which are now established methods, may also be considered prior to radiotherapy (Figure 1).

Cranial irradiation for the treatment of brain tumors may induce infertility in both female and male patients by disruption of the hypothalamic-pituitary-gonadal axis and disturbance of gonadotropin secretion. In some cases, precocious puberty may also be induced by cranial irradiation in childhood, which has been attributed to cortical disruption and loss of inhibition by the hypothalamus.

\section{Fertility preservation options for patients undergoing chemotherapy}

Most chemotherapy protocols combine several agents and there is the possibility of a synergistic gonadotoxic effect. ${ }^{54}$ In females, the primordial ovarian follicles, including oocytes and granulosa cells, are particularly sensitive to alkylating agents, and ovarian failure is common after alkylating treatment. ${ }^{11,15,49,50,55}$ Apoptosis-induced chemotherapy has been demonstrated in vitro ${ }^{53}$ and in vivo ${ }^{56}$ using human ovarian tissue xenotransplanted into the SCID mouse. While claims have been made that chemotherapy may induce ovarian follicle depletion by massive activation of inactive follicles to grow in mice, ${ }^{57}$ these have not been substantiated ${ }^{58}$ or supported by work using human material.

The presence of a rich ovarian reserve with high numbers of follicles in the ovaries, typical during childhood and young adulthood in females, is in itself relatively protective against chemotherapy-induced follicle damage. Girls and very young women who have undergone chemotherapy have a lower risk of ovarian failure and permanent infertility than older women 
after such treatment. ${ }^{11,15}$ Recent follow-up of survivors of cancer in childhood and adolescence corroborates this. ${ }^{55}$ Experimental data from prepubertal and adult mouse models treated with cyclophosphamide do not support the notion that a prepubertal stage would be protective for the primordial follicles. ${ }^{58}$

Toxicity of chemotherapy to growing oocytes has also been demonstrated, ${ }^{59}$ and the clinical recommendation to avoid conception in the 6-month period immediately following completion of chemotherapy is widely practiced. The high risk of teratogenesis during or immediately following chemotherapy has been shown to diminish thereafter, with DNA integrity returning over time after cancer treatment. ${ }^{60}$ No increase in childhood malignancies or genetic malformations have been found in surveys of more than 4,000 children of cancer survivors. ${ }^{61-63}$ Of note, chemotherapeutic agents such as doxorubicin and cyclophosphamide may induce doublestranded DNA breaks. ${ }^{64}$ Oocytes are now known to have the ability to repair double-stranded DNA breaks and some oocytes may eventually repair these mutagenic DNA breaks and survive. This underscores further the importance of giving the ovaries some time to recover after chemotherapy.

In male patients, younger age or prepubertal status does not provide protection against the damage done to the gonads by alkylating agents. ${ }^{54}$ Given that most chemotherapeutic agents are given as part of a combination regimen, it has been difficult to quantify the gonadotoxicity of individual drugs. Table 4 shows the impact of chemotherapeutic agents on the female and male gonads.

Table 4 Chemotherapy agents with high or intermediate gonadotoxic impact in females and males

Prolonged azoospermia in males or amenorrhea in females
High risk
Cyclophosphamide
Ifosphamide
Melphalan
Busulfan
Nitrogen mustard
Procarbazine
Chlorambucil
Intermediate risk
Cisplatin with low cumulative dose
Carboplatin with low cumulative dose
Adriamycin
Low risk
Treatment protocols for Hodgkin's lymphoma without alkylating
agents
Bleomycin
Actinomycin D
Vincristine
Methotrexate
5-Fluorouracil

For patients with a high risk of becoming infertile due to cancer treatment, evidence-based guidelines for fertility preservation following a systematic review and formal procedures for creation of guidelines have been provided by several groups, including the American Society of Clinical Oncology, ${ }^{53}$ which have recently been updated, ${ }^{65}$ the National Institute for Health and Clinical Excellence in the UK, ${ }^{66}$ the Scottish Intercollegiate Guidelines Network, ${ }^{3}$ and the Clinical Oncological Society of Australia, ${ }^{67}$ among others. Reproductive science societies such as the American Society for Reproductive Medicine, ${ }^{68}$ the European Society of Human Reproduction and Embryology, ${ }^{68}$ and the International Society of Fertility Preservation, ${ }^{69}$ have also provided practice guidelines and now promote clinical, educational, and research activities regarding preservation of fertility. Nevertheless, the field of fertility preservation is rapidly evolving, in particular because assisted reproductive technologies, as well as cryopreservation, transplantation, and in vitro culture methods, are developing rapidly, and new treatment options may be available in the near future. When facing gonadotoxic chemotherapy, the options of freezing sperm for males and freezing of embryos for females have been established methods for many years. Recently, due to improvements in freezing of oocytes by vitrification, the American Society of Reproductive Medicine has also introduced vitrification of oocytes as an established method and the updated American Society of Clinical Oncology guidelines reflect this change. ${ }^{65}$ The UK Association of Clinical Embryologists also recommends offering both vitrification of embryos or oocytes for routine fertility preservation. ${ }^{70}$ Additional options, such as freezing of ovarian tissue and prepubertal testicular tissue, are still considered experimental, but are the only options that can be offered to prepubertal children. ${ }^{53}$

\section{Sperm banking for male patients}

Cryopreservation of ejaculated semen is the recommended fertility preservation method for adult males and pubertal boys, and should be offered routinely to cancer patients. ${ }^{71}$ Mature spermatozoa can be found at Tanner III stage with a testis volume above $5 \mathrm{~mL}$; nevertheless, production of spermatozoa is generally effective only at the age of 13-14 years. ${ }^{72}$ Successful sperm cryopreservation has been reported in adolescent patients from the age of 13 years, with a high prevalence of normal sperm counts and semen volume. ${ }^{73,74}$ Cryopreservation of at least three semen samples with an abstinence period of at least 48 hours in between samples is recommended for male patients interested in preserving fertility. ${ }^{75}$ 
In cases of ejaculation failure, search for spermatozoa in a urine sample could be proposed. Testicular sperm extraction can also be performed to retrieve spermatozoa in young men and adolescents. ${ }^{74}$ The use of mature sperm isolated from testicular tissue has been demonstrated to be effective for in vitro fertilization (IVF) and intracytoplasmic sperm injection. ${ }^{44,76}$ Other methods described for retrieval of spermatozoa in adolescents include penile vibratory stimulation and electro-ejaculation.

\section{Cryopreservation of embryos or oocytes for females}

Retrieval of oocytes for freezing or IVF of the retrieved eggs and freezing of embryos are now established methods for adult females. In most countries, women with a partner choose to have embryos frozen. In some countries, women can use donor sperm if they do not have a partner to fertilize their eggs and then freeze the embryos. Ovarian stimulation with gonadotropins is needed to obtain more than one oocyte per cycle and is a key component in the success of IVF cycles as well as cycles aiming to preserve fertility. Although these methods are widely available, the costs inherent in fertility drugs and IVF procedures seem to be a barrier limiting access of patients to preservation of fertility, ${ }^{22}$ and time constraints may also be a limitation for female patients. ${ }^{20}$ Use of random-start antagonist protocols, the feasibility of which is supported by demonstration of up to three major follicle-recruiting waves during a normal menstrual cycle, ${ }^{77}$ has challenged the concept that antral follicles observed in the luteal phase are mostly atretic. Random-start protocols have thus proved to be efficient for fertility preservation while shortening the delay to egg retrieval to about 2 weeks. ${ }^{78,79}$

After freezing of embryos, success rates for transfer of thawed embryos are currently similar to those for fresh embryos if they remain intact after thawing, and this treatment can lead to a $59 \%$ pregnancy rate and a $26 \%$ live birth rate. ${ }^{80}$

The freezing methods used for unfertilized oocytes have advanced remarkably in recent years, with the development of vitrification techniques that have improved oocyte survival and fertilization rates, approaching those reported for fresh oocytes. Worldwide, an increasing number of pregnancies and children born after fertilization of frozen-thawed oocytes has been reported, and although overall pregnancy rates are still relatively lower than those with embryo-freezing, ${ }^{81-83}$ pregnancy rates and live births after thawing and fertilizing frozen eggs are currently reaching those obtained after embryo cryopreservation. ${ }^{84}$ In a recent meta-analysis of individual patient data, raw data from 1,805 women from 10 studies who underwent egg-freezing and attempted pregnancy were reanalyzed. Using these data, the authors were able to calculate specific success rates based on age, number of eggs, and method of freezing. ${ }^{85}$ The formula used can be found at http://www.i-fertility.net/index.php/probability-calc.

\section{Concerns when women with breast cancer are interested in preserving fertility}

Counseling a breast cancer patient regarding her options for fertility preservation should include several important factors other than just the impact of chemotherapy on ovarian reserve. The age of the patient, the number of children desired, concerns regarding type of tumor, presence of BRCA mutation, hormone sensitivity, and concerns regarding the possibility of pregnancy after treatment for breast cancer may vary greatly between patients, so there is no "one-sizefits-all" approach ${ }^{86}$ Early referral has been demonstrated to improve the outcome of embryo and oocyte cryopreservation in women with breast cancer by enabling early initiation of chemotherapy. Early referral for fertility preservation may also improve the likelihood of success by allowing, in some cases, repeated stimulation cycles aiming at obtaining a larger number of oocytes or embryos for cryopreservation before treatment of the cancer. Women with breast cancer and BRCA gene mutations seem to present with reduced ovarian reserve at a young age. ${ }^{87}$

Women with hormone-sensitive tumors who are embarking on a 5-year course of tamoxifen should be informed about the negative impact of increasing age on fertility. The recent ATLAS (Adjuvant Tamoxifen: Longer Against Shorter) study indicated that 10 years of treatment with tamoxifen is superior to a 5-year course, and this will result in a larger proportion of breast cancer patients needing preservation of fertility due to the enforced delay of childbearing. Tamoxifen itself does not affect the ovarian reserve, but the delay in attempting pregnancy for 5-10 years may render some patients infertile by virtue of the impact of aging on their already diminished ovarian reserve. Many breast cancer patients, in particular women who are older than 33 years of age at the time of starting on tamoxifen, may benefit from fertility preservation even when they do not receive chemotherapy $^{88}$ (Figure 1). However, patients presenting with hormone-positive breast cancer have most likely been excluded from any options to preserve fertility, in particular those requiring gonadotropin stimulation, because the supraphysiologic elevation of circulating estradiol levels occurring during gonadotropin stimulation is undesirable and has been 
regarded as potentially harmful. ${ }^{88}$ In fact, because estrogen can have receptor-independent actions, even women who are estrogen receptor-negative are not generally offered the option of embryo or oocyte freezing.

Natural cycle IVF without hormone stimulation has been regarded as a safe alternative in these patients. However, it has reduced efficacy when compared with gonadotropin-stimulated cycles, because it yields only one oocyte or embryo per cycle and the rate of cycle cancellation is high. Ovarian stimulation by selective estrogen receptor modulators and aromatase inhibitors alone or in combination with gonadotropins has been proposed to reduce the potentially harmful impact of high estrogen levels. ${ }^{88}$ Both tamoxifen and letrozole have been investigated and implemented in protocols for ovarian stimulation in women with breast cancer. Stimulation protocols using letrozole alongside gonadotropins have been demonstrated to be the most effective, because they are associated with a higher number of oocytes recovered and fertilized when compared with tamoxifen protocols. ${ }^{89}$ Letrozole is currently used in the treatment of anovulatory infertility in many countries, and its use for fertility treatments aiming at conception has not revealed any increased risks to the fetus. ${ }^{90}$ Follow-up of breast cancer patients who have undergone ovarian stimulation with letrozole for fertility preservation has not identified any detrimental effects on survival in the short-term. ${ }^{91,92}$

Freezing immature oocytes may also be an option for preservation of female fertility in cases where there is not time available for stimulation. Oocytes are retrieved in the natural cycle and frozen at an immature stage or after maturation in vitro. ${ }^{93}$ In vitro maturation of oocytes for fertility preservation has also been reported for immature eggs obtained after gonadotropin stimulation. ${ }^{94}$

\section{Cryopreservation of gonadal tissue}

Cryopreservation of ovarian tissue as a method of fertility preservation for adult females has been demonstrated to be effective, with successful recovery of fertility and live births having been reported after retransplantation of the tissue. ${ }^{95-97}$ In prepubertal children facing gonadotoxic treatments, cryopreservation of gonadal tissue has also been undertaken for fertility preservation. ${ }^{98}$ Methods for freezing adult and prepubertal gonadal tissue have been developed and improved over the years, but methods for using such tissues in fertility treatment by tissue retransplantation or in vitro culture and maturation of gametes are still under development. $53,65,99,100$

\section{Cryopreservation and transplantation of ovarian tissue for females}

Ovarian tissue freezing aims at preserving eggs within primordial follicles in the ovarian cortex. Retrieval of ovarian tissue may be performed by laparoscopy, can be planned shortly after diagnosis of malignant disease has been established, and does not require hormonal stimulation. ${ }^{98}$ It is preferable to retrieve ovarian tissue for cryopreservation before a gonadotoxic treatment is initiated; however, it may still be worthwhile after the first courses of chemotherapy in young women and girls, who normally have a high number of primordial follicles in their ovaries. ${ }^{14}$

Transplantation of frozen-thawed ovarian cortical tissue has been demonstrated to provide recovery of ovarian function ${ }^{101}$ and restore spontaneous fertility. ${ }^{97,102}$ Hormonal stimulation with gonadotropins and success after in vitro fertilization have also been reported in women who have undergone retransplantation of ovarian tissue. ${ }^{96}$ Ovarian tissue can be transplanted orthotopically, ie, at the anatomic intrapelvic ovarian site, or heterotopically, ie, at other places, including extrapelvic sites. ${ }^{103,104}$ The techniques used for transplantation are currently being improved, in particular aiming at reducing initial ischemic follicle loss in the transplanted tissue, which is a concern. ${ }^{105,106}$

Autotransplantation of ovarian tissue in patients who have suffered from systemic hematologic malignancy is not recommended due to the high risk of retransmission of malignancy, and only patients with a cancer diagnosis associated with a negligible or no risk of ovarian compromise should be considered for future autotransplantation. ${ }^{107-109}$ Methods for detection of cancer cells in the ovarian tissue of patients who have suffered from hematologic malignancy are under development, including immunohistochemistry or the polymerase chain reaction, which can be attempted if there is a genetic marker. ${ }^{110,111}$ Investigation for residual malignant cells in ovarian tissue has been done by xenotransplantation in the immunodeficient SCID mouse, but this approach has not been shown to be of clinical use. Ovarian tissue cryopreservation and transplantation has been shown not to interfere with appropriate genomic imprinting in mouse pups, ${ }^{112}$ but further studies in other animal models are needed.

\section{Future possibilities: in vitro culture} and maturation of ovarian follicles

Ovarian follicles cultured or isolated within a piece of thawed tissue will be the option for patients with hematologic and ovarian malignancies, given that tissue retransplantation is considered unsafe due to the risk of reintroducing malignant cells. Although many improvements have been reported for 
in vitro culture of follicles at early stages aiming at developing them into competent mature follicles, these methods are still in development. ${ }^{100,113-115}$ The normality of imprinted genes of cryobanked oocytes cultured and matured in vitro has yet to be verified experimentally.

\section{Prepubertal testicular tissue cryopreservation}

In adult males, mature spermatozoa can be recovered from testicular tissue biopsies and several cryopreservation protocols have been developed. ${ }^{116}$ In prepubertal boys, there is only the possibility to preserve spermatogonia, because no mature sperm yet exist. Success has been reported in cryopreservation methods for prepubertal testicular tissue, ${ }^{117}$ but when preserving prepubertal tissue, more research is still needed aiming at using the frozen-thawed tissue to obtain mature spermatozoa in vitro. Research suggests that in vitro spermatogenesis is likely to be the safest option for boys suffering from hematologic malignancies, which might be retransmitted by retransplantation. Isolation of spermatogonia from contaminating leukemia cells by flow cytometry of a human testis cell suspension has been reported, ${ }^{118}$ and spermatogonial transplantation into the testes may be an option in the future. ${ }^{119}$

Cryopreservation of gonadal tissue offers hope for survivors of childhood cancer, but also requires careful oversight. Experimental methods for fertility preservation should only be offered to patients at specialized centers working with ethically approved research protocols, and only in cases where the recognized risks associated with the procedure are minimal. Whenever possible, these procedures should be performed with other necessary procedures, such as port placement or biopsies to reduce the need for additional surgery. ${ }^{98}$

\section{Preventing gonadal damage in females or males by gonadal suppression}

It has been hypothesized that administration of gonadotropinreleasing hormone analogs to suppress female gonadal function transiently during chemotherapy could prevent ovarian follicle destruction by inducing a prepubertal hormonal milieu, aiming to maintain the follicles in a dormant state. However, the pool of primordial follicles is normally nonproliferating. The data show that these follicles lack follicle-stimulating hormone receptors ${ }^{120}$ and that their initial recruitment is not controlled by gonadotropins, ${ }^{121}$ thus hormonal manipulation by suppressing gonadotropin release is not likely to affect them. ${ }^{120}$ In mouse models, prepubertal status has not been protective against the follicle depletion induced by cyclophosphamide at doses similar to those used therapeutically in humans. ${ }^{58}$

In females, the vast majority of clinical studies investigating gonadal protection by gonadotropin-releasing hormone analogs during chemotherapy have been small, retrospective, and uncontrolled. A significant number of these studies used resumption of menses as a surrogate marker for fertility and many reported a higher frequency of menstrual cycles in women who have received gonadotropin-releasing hormone analogs, but none has demonstrated a beneficial effect regarding fertility recovery. The current data indicate that infertility is increased after chemotherapy, even if menstrual cycles are resumed. ${ }^{122}$ A recent review of 12 trials, both randomized and nonrandomized, in women with breast cancer found the benefit of cotreatment with gonadotropin-releasing hormone analogs to be uncertain in female fertility. ${ }^{123}$

In males, a young age or prepubertal status do not provide protection against damage to the gonads by cytotoxic agents. ${ }^{54,124}$ Suppression of gonadotropins and testosterone secretion does not seem to affect the kinetics of developing cells and only blocks completion of spermatogenesis, ${ }^{125}$ and experimental studies using animal models have reported conflicting results. ${ }^{126}$ Clinical studies of males with Hodgkin's lymphoma or testicular cancer ${ }^{126}$ have not found any fertility-protecting effects after using these agents. Based on the preponderance of evidence, gonadotropin-releasing hormone analogs should not be considered as a proven method of fertility preservation in females or males. However, there are other promising pharmacologic agents, such as the Sphingosine-1-phosphate, which may protect ovarian reserve against chemotherapy. ${ }^{127}$

\section{Current deficiencies in provision of information and fertility preservation}

Despite the evidence that fertility loss in survivors of cancer is related to psychologic distress and impaired quality of life, ${ }^{20,128-130}$ many cancer patients of reproductive age still do not receive adequate information or referral to a reproductive specialist for fertility preservation. ${ }^{23,71,131,132}$ This is in contrast with data indicating that approximately three of four cancer patients younger than 35 years and childless at the time of cancer treatment may be interested in having children in the future. ${ }^{18}$ In males, it has been shown that the expected number of patients who should bank sperm before cancer treatment is consistently lower than the expected number of cancer cases in young men. ${ }^{71}$ Reluctance to delay initiation of cancer treatment, difficulties in communicating, lack of knowledge, and concerns regarding the costs of freezing sperm have been 
discussed, among other reasons. ${ }^{71,132}$ Regarding females, access to fertility preservation seems to be more difficult than for males, regardless of economic issues, ${ }^{23}$ which are a recognized barrier for females in some countries. ${ }^{22}$

To allow cancer patients to make informed decisions regarding their reproductive potential, information on the impact of cancer treatment on fertility and on the available options for fertility preservation should be presented to them in a timely manner. Several multidisciplinary groups, most of them based on oncology and reproductive societies, have organized educational activities and provide resources for both health care personnel and patients regarding fertility preservation, as well as numerous nonprofit patient associations.

\section{Conclusion}

The majority of children, adolescents, and young adults diagnosed with cancer today will become long-term survivors. Many surveys of cancer survivors have found that these patients are at increased risk of emotional distress if they become infertile as a result of their treatment. Health care providers should be prepared to discuss the negative impact of cancer therapy on reproductive health with their patients in the same way as any other risks of cancer treatment are discussed. The possibility of using fertility preservation methods should be presented to all patients even if they are ambivalent at the time. Recent reports indicate that fertility preservation may be offered in a safe context, without any risk of delaying initiation of cancer treatment. In this context, prompt referral may increase the cancer patient's chances of receiving appropriate counseling and improve the success of fertility preservation. Interdisciplinary collaboration between oncologists and reproductive endocrinologists, development of local clinical guidelines, and educational activities should be encouraged.

\section{Acknowledgments}

KARW is supported by The Swedish Research Council and Stockholm County Council. KO is supported by the National Institute of Health (grants RO1 HD053112 and R21 HD061259).

\section{Disclosure}

The authors report no conflicts of interest in this work.

\section{References}

1. Swedish Official Statistics. Cancer Incidence in Sweden 2011. Updated 2012. Available from: http://www.socialstyrelsen.se/Lists/ Artikelkatalog/Attachments/18919/2012-12-19.pdf. Accessed October 30, 2013.
2. International Agency for Research on Cancer. EUCAN. Cancer Factsheets. 2013. Available from: http://eco.iarc.fr/EUCAN/. Accessed October 30, 2013.

3. Health Improvement Scotland. Long term follow up of survivors of childhood cancer. A national clinical guideline. 2013. Available from: http://www.sign.ac.uk/pdf/sign132.pdf. Accessed October 30, 2013.

4. United Kingdom Childhood Cancer Study. Subfertility risk consensus document, 2005. Available from: http://www.ukccs.org/. Accessed October 30, 2013.

5. Burstein HJ, Winer EP. Primary care for survivors of breast cancer. N Engl J Med. 2000;343(15):1086-1094.

6. Goodwin PJ, Ennis M, Pritchard KI, Trudeau M, Hood N. Risk of menopause during the first year after breast cancer diagnosis. J Clin Oncol. 1999;17(8):2365-2370.

7. Grigg A. The impact of conventional and high-dose therapy for lymphoma on fertility. Clin Lymphoma. 2004;5(2):84-88.

8. Howell SJ, Shalet SM. Spermatogenesis after cancer treatment: damage and recovery. J Natl Cancer Inst Monogr. 2005;34:12-17.

9. Wallace WH, Thomson AB, Kelsey TW. The radiosensitivity of the human oocyte. Hum Reprod. 2003;18(1):117-121.

10. Wallace WH, Thomson AB, Saran F, Kelsey TW. Predicting age of ovarian failure after radiation to a field that includes the ovaries. Int $J$ Radiat Oncol Biol Phys. 2005;62(3):738-744.

11. Wallace WH, Anderson RA, Irvine DS. Fertility preservation for young patients with cancer: who is at risk and what can be offered? Lancet Oncol. 2005;6(4):209-218.

12. Fleischer RT, Vollenhoven BJ, Weston GC. The effects of chemotherapy and radiotherapy on fertility in premenopausal women. Obstet Gynecol Surv. 2011;66(4):248-254.

13. Wo JY, Viswanathan AN. Impact of radiotherapy on fertility, pregnancy, and neonatal outcomes in female cancer patients. Int $J$ Radiat Oncol Biol Phys. 2009;73(5):1304-1312.

14. Wallberg KA, Keros V, Hovatta O. Clinical aspects of fertility preservation in female patients. Pediatr Blood Cancer. 2009;53(2):254-260.

15. Rodriguez-Wallberg KA. Principles of cancer treatment: impact on reproduction. Adv Exp Med Biol. 2012;732:1-8.

16. Pacey AA. Fertility issues in survivors from adolescent cancers. Cancer Treat Rev. 2007;33(7):646-655.

17. Schover LR. Psychosocial aspects of infertility and decisions about reproduction in young cancer survivors: a review. Med Pediatr Oncol. 1999;33(1):53-59.

18. Schover LR, Rybicki LA, Martin BA, Bringelsen KA. Having children after cancer. A pilot survey of survivors' attitudes and experiences. Cancer. 1999;86(4):697-709.

19. Duffy C, Allen S. Medical and psychosocial aspects of fertility after cancer. Cancer J. 2009;15(1):27-33.

20. Rosen A, Rodriguez-Wallberg KA, Rosenzweig L. Psychosocial distress in young cancer survivors. Semin Oncol Nurs. 2009;25(4):268-277.

21. Howard-Anderson J, Ganz PA, Bower JE, Stanton AL. Quality of life, fertility concerns, and behavioral health outcomes in younger breast cancer survivors: a systematic review. J Natl Cancer Inst. 2012;104(5):386-405.

22. Quinn GP, Vadaparampil ST, Bell-Ellison BA, Gwede CK, Albrecht TL. Patient-physician communication barriers regarding fertility preservation among newly diagnosed cancer patients. Soc Sci Med. 2008;66(3):784-789.

23. Armuand GM, Rodriguez-Wallberg KA, Wettergren L, et al. Sex differences in fertility-related information received by young adult cancer survivors. J Clin Oncol. 2012;30(17):2147-2153.

24. Letourneau JM, Smith JF, Ebbel EE, et al. Racial, socioeconomic, and demographic disparities in access to fertility preservation in young women diagnosed with cancer. Cancer. 2012;118(18):4579-4588.

25. National Cancer Institute. SEER Cancer Statistics Review 1975-2007. Updated 2011. Available from: http://seer.cancer.gov/archive/ csr/1975_2007/. Accessed October 30, 2013. 
26. Siegel R, Ma J, Zou Z, Jemal A. Cancer statistics. 2014. CA: A Cancer Journal for Clinicians. 2014;64:9-29.

27. Dargent D, Mathevet P. [Radical laparoscopic vaginal hysterectomy]. J Gynecol Obstet Biol Reprod (Paris). 1992;21(6):709-710.

28. Morice P, Uzan C, Gouy S, et al. [Effects of radiotherapy (external and/or internal) and chemotherapy on female fertility]. Bull Acad Natl Med. 2010;194(3):481-492. French.

29. Liou WS, Yap OW, Chan JK, Westphal LM. Innovations in fertility preservation for patients with gynecologic cancers. Fertil Steril. 2005;84(6):1561-1573.

30. Abu-Rustum NR, Sonoda Y. Fertility-sparing surgery in early-stage cervical cancer: indications and applications. J Natl Compr Canc Netw. 2010;8(12):1435-1438.

31. Plante M, Gregoire J, Renaud MC, Roy M. The vaginal radical trachelectomy: an update of a series of 125 cases and 106 pregnancies. Gynecol Oncol. 2011;121(2):290-297.

32. Li J, Li Z, Wang H, et al. Radical abdominal trachelectomy for cervical malignancies: surgical, oncological and fertility outcomes in 62 patients. Gynecol Oncol. 2011;121(3):565-570.

33. Testa R, Ramirez PT, Ferreyra H, et al. Abdominal radical trachelectomy: a safe and feasible option for fertility preservation in developing countries. J Low Genit Tract Dis. 2013;17(4):378-384.

34. Speiser D, Köhler C, Schneider A, Mangler M. Radical vaginal trachelectomy: a fertility-preserving procedure in early cervical cancer in young women. Dtsch Arztebl Int. 2013;110(17):289-295.

35. Pareja R, Rendón GJ, Sanz-Lomana CM, Monzón O, Ramirez PT. Surgical, oncological, and obstetrical outcomes after abdominal radical trachelectomy - a systematic literature review. Gynecol Oncol. 2013;131(1):77-82.

36. Vercellino GF, Piek JM, Schneider A, et al. Laparoscopic lymph node dissection should be performed before fertility preserving treatment of patients with cervical cancer. Gynecol Oncol. 2012;126(3):325-329.

37. Wethington SL, Sonoda Y, Park KJ, et al. Expanding the indications for radical trachelectomy: a report on 29 patients with stage IB1 tumors measuring 2 to 4 centimeters. Int J Gynecol Cancer. 2013;23(6): 1092-1098.

38. Kesic V, Rodolakis A, Denschlag D, et al. Fertility preserving management in gynecologic cancer patients: the need for centralization. Int J Gynecol Cancer. 2010;20(9):1613-1619.

39. Ungár L, Smith JR, Pálfalvi L, Del Priore G. Abdominal radical trachelectomy during pregnancy to preserve pregnancy and fertility. Obstet Gynecol. 2006;108(3 Pt 2):811-814.

40. Sioutas A, Schedvins K, Larson B, Gemzell-Danielsson K. Three cases of vaginal radical trachelectomy during pregnancy. Gynecol Oncol. 2011;121(2):420-421.

41. Sabanegh ES Jr, Ragheb AM. Male fertility after cancer. Urology. 2009; 73(2):225-231.

42. Heidenreich A, Weissbach L, Höltl W, et al. Organ sparing surgery for malignant germ cell tumor of the testis. J Urol. 2001;166(6): 2161-2165.

43. Baniel J, Sella A. Sperm extraction at orchiectomy for testis cancer. Fertil Steril. 2001;75(2):260-262.

44. Choi BB, Goldstein M, Moomjy M, Palermo G, Rosenwaks Z, Schlegel PN. Births using sperm retrieved via immediate microdissection of a solitary testis with cancer. Fertil Steril. 2005;84(5):1508.

45. Schrader M, Müller M, Sofikitis N, Straub B, Krause H, Miller K. "Onco-tese": testicular sperm extraction in azoospermic cancer patients before chemotherapy-new guidelines? Urology. 2003;61(2):421-425.

46. Gosden RG, Wade JC, Fraser HM, Sandow J, Faddy MJ. Impact of congenital or experimental hypogonadotrophism on the radiation sensitivity of the mouse ovary. Hum Reprod. 1997;12(11):2483-2488.

47. Speiser B, Rubin P, Casarett G. Aspermia following lower truncal irradiation in Hodgkin's disease. Cancer. 1973;32(3):692-698.

48. Rodriguez-Wallberg KA, Oktay K. Fertility preservation medicine: options for young adults and children with cancer. J Pediatr Hematol Oncol. 2010;32(5):390-396.
49. Sklar C. Growth and endocrine disturbances after bone marrow transplantation in childhood. Acta Paediatr Suppl. 1995;411:57-61.

50. Thibaud E, Rodriguez-Macias K, Trivin C, Espérou H, Michon J, Brauner R. Ovarian function after bone marrow transplantation during childhood. Bone Marrow Transplant. 1998;21(3):287-290.

51. Green DM, Sklar CA, Boice JD Jr, et al. Ovarian failure and reproductive outcomes after childhood cancer treatment: results from the Childhood Cancer Survivor Study. J Clin Oncol. 2009;27(14):2374-2381.

52. Shalet SM, Tsatsoulis A, Whitehead E, Read G. Vulnerability of the human Leydig cell to radiation damage is dependent upon age. J Endocrinol. 1989;120(1):161-165.

53. Lee SJ, Schover LR, Partridge AH, et al. American Society of Clinical Oncology recommendations on fertility preservation in cancer patients. J Clin Oncol. 2006;24(18):2917-2931.

54. Hudson MM. Reproductive outcomes for survivors of childhood cancer. Obstet Gynecol. 2010;116(5):1171-1183.

55. Barton SE, Najita JS, Ginsburg ES, et al. Infertility, infertility treatment, and achievement of pregnancy in female survivors of childhood cancer: a report from the Childhood Cancer Survivor Study cohort. Lancet Oncol. 2013;14(9):873-881.

56. Oktem O, Oktay K. A novel ovarian xenografting model to characterize the impact of chemotherapy agents on human primordial follicle reserve. Cancer Res. 2007;67(21):10159-10162.

57. Kalich-Philosoph L, Roness H, Carmely A, et al. Cyclophosphamide triggers follicle activation and "burnout"; AS101 prevents follicle loss and preserves fertility. Sci Transl Med. 2013;5(185):185ra62.

58. Rodriguez-Wallberg KA, Alonso de Mena S, Malm E, Larsson A, Kuiper R, Hassan M. Pre-pubertal status does not protect against follicle depletion induced by cyclophosphamide in mice. A randomized study. Hum Reprod. 2013;28 Suppl 1:P321.

59. Meirow D, Epstein M, Lewis H, Nugent D, Gosden RG. Administration of cyclophosphamide at different stages of follicular maturation in mice: effects on reproductive performance and fetal malformations. Hum Reprod. 2001;16(4):632-637.

60. Simon B, Lee SJ, Partridge AH, Runowicz CD. Preserving fertility after cancer. CA Cancer J Clin. 2005;55(4):211-228.

61. Dodds L, Marrett LD, Tomkins DJ, Green B, Sherman G. Casecontrol study of congenital anomalies in children of cancer patients. BMJ. 1993;307(6897):164-168.

62. Langagergaard V, Gislum M, Skriver MV, et al. Birth outcome in women with breast cancer. Br J Cancer. 2006;94(1):142-146.

63. Dalberg K, Eriksson J, Holmberg L. Birth outcome in women with previously treated breast cancer - a population-based cohort study from Sweden. PLoS Med. 2006;3(9):e336.

64. Soleimani R, Heytens E, Darzynkiewicz Z, Oktay K. Mechanisms of chemotherapy-induced human ovarian aging: double strand DNA breaks and microvascular compromise. Aging (Albany NY). 2011;3(8): 782-793.

65. Loren AW, Mangu PB, Beck LN, et al; American Society of Clinical Oncology. Fertility preservation for patients with cancer: American Society of Clinical Oncology Clinical Practice Guideline Update. J Clin Oncol. 2013;31(19):2500-2510.

66. National Institute for Health Care and Excellence. Fertility: assessment and treatment for people with fertility problems. Available from: http:// publications.nice.org.uk/fertility-cg156. Accessed October 30, 2013.

67. Cancer Council Australia [homepage on the Internet]. Sydney: Cancer Council Australia. Available from: http://www.cancer.org.au. Accessed November 19, 2013.

68. ReproductiveFacts.org [homepage on the Internet]. Birmingham, AL: The American Society for Reproductive Medicine. Available from: http://www.asrm.org. Accessed November 19, 2013.

69. International Society for Fertility Presentation [homepage on the Internet]. Kansas: International Society for Fertility Presentation. Available from: http://www.isfp-fertility.org. Accessed November 19, 2013.

70. Brison D, Cutting R, Clarke H, Wood M. ACE consensus meeting report: oocyte and embryo cryopreservation Sheffield 17.05.11. Hum Fertil (Camb). 2012;15(2):69-74. 
71. Pacey AA, Eiser C. Banking sperm is only the first of many decisions for men: what health care professionals and men need to know. Hum Fertil (Camb). 2011;14(4):208-217.

72. Guérin JF. [Testicular tissue cryoconservation for prepubertal boy: indications and feasibility]. Gynecol Obstet Fertil. 2005;33(10): 804-808. French.

73. Bahadur G, Ling KL, Hart R, et al. Semen quality and cryopreservation in adolescent cancer patients. Hum Reprod. 2002;17(12): 3157-3161.

74. Menon S, Rives N, Mousset-Siméon N, et al. Fertility preservation in adolescent males: experience over 22 years at Rouen University Hospital. Hum Reprod. 2009;24(1):37-44.

75. Meseguer M, Molina N, García-Velasco JA, Remohí J, Pellicer A, Garrido N. Sperm cryopreservation in oncological patients: a 14-year follow-up study. Fertil Steril. 2006;85(3):640-645.

76. Morey AF, Deshon GE Jr, Rozanski TA, Dresner ML. Technique of biopty gun testis needle biopsy. Urology. 1993;42(3):325-326.

77. Baerwald AR, Adams GP, Pierson RA. A new model for ovarian follicular development during the human menstrual cycle. Fertil Steril. 2003;80(1):116-122.

78. von Wolff M, Thaler CJ, Frambach T, et al. Ovarian stimulation to cryopreserve fertilized oocytes in cancer patients can be started in the luteal phase. Fertil Steril. 2009;92(4):1360-1365.

79. Sönmezer M, Türkçüoğlu I, Coşkun U, Oktay K. Random-start controlled ovarian hyperstimulation for emergency fertility preservation in letrozole cycles. Fertil Steril. 2011;95(6):2125. e9-e11.

80. Marrs RP, Greene J, Stone BA. Potential factors affecting embryo survival and clinical outcome with cryopreserved pronuclear human embryos. Am J Obstet Gynecol. 2004;190(6):1766-1771.

81. Oktay K, Cil AP, Bang H. Efficiency of oocyte cryopreservation: a meta-analysis. Fertil Steril. 2006;86(1):70-80.

82. Practice Committee of American Society for Reproductive Medicine; Practice Committee of Society for Assisted Reproductive Technology. Ovarian tissue and oocyte cryopreservation. Fertil Steril. 2008; 90(Suppl 5):S241-S246.

83. Practice Committees of American Society for Reproductive Medicine; Society for Assisted Reproductive Technology. Mature oocyte cryopreservation: a guideline. Fertil Steril. 2013;99(1):37-43.

84. Noyes N, Porcu E, Borini A. Over 900 oocyte cryopreservation babies born with no apparent increase in congenital anomalies. Reprod Biomed Online. 2009;18(6):769-776.

85. Cil AP, Bang H, Oktay K. Age-specific probability of live birth with oocyte cryopreservation: an individual patient data meta-analysis. Fertil Steril. 2013;100(2):492-499. e3.

86. Rodriguez-Wallberg KA, Oktay K. Fertility preservation and pregnancy in women with and without BRCA mutation-positive breast cancer. Oncologist. 2012;17(11):1409-1417.

87. Titus S, Li F, Stobezki R, et al. Impairment of BRCA1-related DNA double-strand break repair leads to ovarian aging in mice and humans. Sci Transl Med. 2013;5(172):172ra21.

88. Rodriguez-Wallberg KA, Oktay K. Fertility preservation in women with breast cancer. Clin Obstet Gynecol. 2010;53(4):753-762.

89. Oktay K, Buyuk E, Libertella N, Akar M, Rosenwaks Z. Fertility preservation in breast cancer patients: a prospective controlled comparison of ovarian stimulation with tamoxifen and letrozole for embryo cryopreservation. J Clin Oncol. 2005;23(19):4347-4353.

90. Tulandi T, Martin J, Al-Fadhli R, et al. Congenital malformations among 911 newborns conceived after infertility treatment with letrozole or clomiphene citrate. Fertil Steril. 2006;85(6):1761-1765.

91. Azim AA, Costantini-Ferrando M, Oktay K. Safety of fertility preservation by ovarian stimulation with letrozole and gonadotropins in patients with breast cancer: a prospective controlled study. J Clin Oncol. 2008;26(16):2630-2635

92. Oktay K, Lee S, Kim JY, et al. Long-term outcomes and safety of letrozole-FSH protocol in women with breast cancer undergoing fertility preservation: a prospective-controlled study. Fertil Steril. 2010;94 (4 Suppl 1):S11.
93. Chian RC, Gilbert L, Huang JY, et al. Live birth after vitrification of in vitro matured human oocytes. Fertil Steril. 2009;91(2): 372-376.

94. Oktay K, Buyuk E, Rodriguez-Wallberg KA, Sahin G. In vitro maturation improves oocyte or embryo cryopreservation outcome in breast cancer patients undergoing ovarian stimulation for fertility preservation. Reprod Biomed Online. 2010;20(5):634-638.

95. Donnez J, Dolmans MM, Demylle D, et al. Livebirth after orthotopic transplantation of cryopreserved ovarian tissue. Lancet. 2004;364(9443):1405-1410.

96. Donnez J, Silber S, Andersen CY, et al. Children born after autotransplantation of cryopreserved ovarian tissue. a review of 13 live births. Ann Med. 2011;43(6):437-450.

97. Oktay K, Türkçüoğlu I, Rodriguez-Wallberg KA. Four spontaneous pregnancies and three live births following subcutaneous transplantation of frozen banked ovarian tissue: what is the explanation? Fertil Steril. 2011;95(2):804. e7-e10.

98. Rodriguez-Wallberg KA, Borgstrom B, Sheikhi M. Lundqvist ML, Hovatta O. Cryopreservation of oocytes and gonadal tissue in a large fertility preservation programme at a teaching hospital. Hum Reprod. 2010;25 Supp1 1:i104.

99. von Wolff M, Donnez J, Hovatta O, et al. Cryopreservation and autotransplantation of human ovarian tissue prior to cytotoxic therapy - a technique in its infancy but already successful in fertility preservation. Eur J Cancer. 2009;45(9):1547-1553.

100. Smitz J, Dolmans MM, Donnez J, et al. Current achievements and future research directions in ovarian tissue culture, in vitro follicle development and transplantation: implications for fertility preservation. Hum Reprod Update. 2010;16(4):395-414.

101. Oktay K, Karlikaya G. Ovarian function after transplantation of frozen, banked autologous ovarian tissue. N Engl J Med. 2000;342(25): 1919.

102. Andersen CY, Rosendahl M, Byskov AG, et al. Two successful pregnancies following autotransplantation of frozen/thawed ovarian tissue. Hum Reprod. 2008;23(10):2266-2272.

103. Oktay K, Buyuk E, Veeck L, et al. Embryo development after heterotopic transplantation of cryopreserved ovarian tissue. Lancet. 2004;363(9412):837-840.

104. Sonmezer M, Oktay K. Orthotopic and heterotopic ovarian tissue transplantation. Best Pract Res Clin Obstet Gynaecol. 2010;24(1): 113-126.

105. Rodriguez-Wallberg KA, Oktay K. Recent advances in oocyte and ovarian tissue cryopreservation and transplantation. Best Pract Res Clin Obstet Gynaecol. 2012;26(3):391-405.

106. Soleimani R, Heytens E, Oktay K. Enhancement of neoangiogenesis and follicle survival by sphingosine-1-phosphate in human ovarian tissue xenotransplants. PLoS One. 2011;29;6(4):e19475.

107. Dolmans MM, Luyckx V, Donnez J, Andersen CY, Greve T. Risk of transferring malignant cells with transplanted frozen-thawed ovarian tissue. Fertil Steril. 2013;99(6):1514-1522.

108. Greve T, Clasen-Linde E, Andersen MT, et al. Cryopreserved ovarian cortex from patients with leukemia in complete remission contains no apparent viable malignant cells. Blood. 2012;120(22):4311-4316.

109. Rosendahl M, Greve T, Andersen CY. The safety of transplanting cryopreserved ovarian tissue in cancer patients: a review of the literature. J Assist Reprod Genet. 2013;30(1):11-24.

110. Meirow D, Hardan I, Dor J, et al. Searching for evidence of disease and malignant cell contamination in ovarian tissue stored from hematologic cancer patients. Hum Reprod. 2008;23(5):1007-1013.

111. Greve T, Wielenga VT, Grauslund M, et al. Ovarian tissue cryopreserved for fertility preservation from patients with Ewing or other sarcomas appear to have no tumour cell contamination. Eur J Cancer. 2013;49(8):1932-1938.

112. Sauvat F, Capito C, Sarnacki S, et al. Immature cryopreserved ovary restores puberty and fertility in mice without alteration of epigenetic marks. PLoS One. 2008;3(4):e1972. 
113. Carlsson IB, Scott JE, Visser JA, Ritvos O, Themmen AP, Hovatta O. Anti-Mullerian hormone inhibits initiation of growth of human primordial ovarian follicles in vitro. Hum Reprod. 2006;21(9):2223-2227.

114. Telfer EE, McLaughlin M, Ding C, Thong KJ. A two-step serum-free culture system supports development of human oocytes from primordial follicles in the presence of activin. Hum Reprod. 2008;23(5):1151-1158.

115. Telfer EE, Zelinski MB. Ovarian follicle culture: advances and challenges for human and nonhuman primates. Fertil Steril. 2013;99(6): 1523-1533.

116. Baert Y, Van Saen D, Haentjens P, In't Veld P, Tournaye H, Goossens E. What is the best cryopreservation protocol for human testicular tissue banking? Hum Reprod. 2013;28(7):1816-1826.

117. Keros V, Hultenby K, Borgström B, Fridström M, Jahnukainen K, Hovatta O. Methods of cryopreservation of testicular tissue with viable spermatogonia in pre-pubertal boys undergoing gonadotoxic cancer treatment. Hum Reprod. 2007;22(5):1384-1395.

118. Dovey SL, Valli H, Hermann BP, et al. Eliminating malignant contamination from therapeutic human spermatogonial stem cells. 2013;123(4):1833-1843.

119. Goossens E, Van Saen D, Tournaye H. Spermatogonial stem cell preservation and transplantation: from research to clinic. Hum Reprod. 2013;28(4):897-907.

120. Oktay K, Briggs D, Gosden RG. Ontogeny of follicle-stimulating hormone receptor gene expression in isolated human ovarian follicles. J Clin Endocrinol Metab. 1997;82(11):3748-3751.

121. McGee EA, Hsueh AJ. Initial and cyclic recruitment of ovarian follicles. Endocr Rev. 2000;21(2):200-201.

122. Letourneau JM, Ebbel E, Katz P, et al. The prevalence of self-reported reproductive impairment in young female cancer survivors throuhgout California. Fertil Steril. 2010;94(4):510.

123. Turner NH, Partridge A, Sanna G, Di Leo A, Biganzoli L. Utility of gonadotropin-releasing hormone agonists for fertility preservation in young breast cancer patients: the benefit remains uncertain. Ann Oncol. 2013;24(9):2224-2235.

124. Meistrich ML. Male gonadal toxicity. Pediatr Blood Cancer. 2009;53(2):261-266.
125. Meistrich ML, Wilson G, Ye WS, Kurdoglu B, Parchuri N, Terry NH Protection from procarbazine-induced testicular damage by hormonal pretreatment does not involve arrest of spermatogonial proliferation. Cancer Res. 1994;54(4):1027-1034.

126. Meistrich ML, Shetty G. Hormonal suppression for fertility preservation in males and females. Reproduction. 2008;136(6):691-701.

127. Li F, Turan V, Lierman S, Cuvelier C, De Sutter P, Oktay K. Sphingosine-1-phosphate prevents chemotherapy-induced human primordial follicle death. Hum Reprod. 2014;29(1):107-113.

128. Skinner R, Wallace WH, Levitt GA; UK Children's Cancer Study Group Late Effects Group. Long-term follow-up of people who have survived cancer during childhood. Lancet Oncol. 2006;7(6):489-498.

129. Byrne J, Fears TR, Steinhorn SC, et al. Marriage and divorce after childhood and adolescent cancer. JAMA. 1989;262(19):2693-2699.

130. Partridge AH, Gelber S, Peppercorn J, et al. Web-based survey of fertility issues in young women with breast cancer. $J$ Clin Oncol. 2004;22(20):4174-4183

131. Forman EJ, Anders CK, Behera MA. Pilot survey of oncologists regarding treatment-related infertility and fertility preservation in female cancer patients. J Reprod Med. 2009;54(4):203-207.

132. Merrick H, Wright E, Pacey AA, Eiser C. Finding out about sperm banking: what information is available online for men diagnosed with cancer? Hum Fertil (Camb). 2012;15(3):121-128.

133. Sonoda Y, Chi DS, Carter J, Barakat RR, Abu-Rustum NR. Initial experience with Dargent's operation: the radical vaginal trachelectomy. Gynecol Oncol. 2008;108(1):214-219.

134. Morris RT, Gershenson DM, Silva EG, Follen M, Morris M, Wharton JT. Outcome and reproductive function after conservative surgery for borderline ovarian tumors. Obstet Gynecol. 2000;95(4):541-547.

135. Morice P, Camatte S, Wicart-Poque F, et al. Results of conservative management of epithelial malignant and borderline ovarian tumours. Hum Reprod Update. 2003;9(2):185-192.

136. Tangir J, Zelterman D, Ma W, Schwartz PE. Reproductive function after conservative surgery and chemotherapy for malignant germ cell tumors of the ovary. Obstet Gynecol. 2003;101(2):251-257.

137. Seli E, Tangir J. Fertility preservation options for female patients with malignancies. Curr Opin Obstet Gynecol. 2005;17(3):299-308.
Cancer Management and Research

\section{Publish your work in this journal}

Cancer Management and Research is an international, peer-reviewed open access journal focusing on cancer research and the optimal use of preventative and integrated treatment interventions to achieve improved outcomes, enhanced survival and quality of life for the cancer patient The journal welcomes original research, clinical \& epidemiological

\section{Dovepress}

studies, reviews \& evaluations, guidelines, expert opinion \& commentary, case reports \& extended reports. The manuscript management system is completely online and includes a very quick and fair peerreview system, which is all easy to use. Visit http://www.dovepress.com/ testimonials.php to read real quotes from published authors. 